\title{
Gene expression pattern of the epidermal growth factor receptor family and LRIG1 in renal cell carcinoma
}

\author{
Marcus Thomasson ${ }^{1 *}$, Håkan Hedman ${ }^{1}$, Börje Ljungberg ${ }^{2}$ and Roger Henriksson ${ }^{1}$
}

\begin{abstract}
Background: Previous studies have revealed altered expression of epidermal growth factor receptor (EGFR)-family members and their endogenous inhibitor leucine-rich and immunoglobulin-like domains 1 (LRIG1) in renal cell carcinoma (RCC). In this study, we analyzed the gene expression levels of EGFR-family members and LRIG1, and their possible associations with clinical parameters in various types of RCC.

Methods: Gene expression levels of EGFR-family members and LRIG1 were analyzed in 104 RCC samples, including 81 clear cell RCC (ccRCC), 15 papillary RCC (pRCC), and 7 chromophobe RCC (chRCC) by quantitative real-time RT-PCR. Associations between gene expression levels and clinical data, including tumor grade, stage, and patient survival were statistically assessed.
\end{abstract}

Results: Compared to kidney cortex, EGFR was up-regulated in $C C R C C$ and PRCC, LRIG1 and ERBB2 were down-regulated in CCRCC, and ERBB4 was strongly down-regulated in all RCC types. ERBB3 expression did not differ between RCC types or between RCC and the kidney cortex. The expression of the analyzed genes did not correlate with patient outcome.

Conclusions: This study revealed that the previously described up-regulation of EGFR and down-regulation of ERBB4 occurred in all analyzed RCC types, whereas down-regulation of ERBB2 and LRIG1 was only present in cCRCC. These observations illustrate the need to evaluate the different RCC types individually when analyzing molecules of interest and potential biological markers.

Keywords: Renal cell carcinoma, EGFR, ERBB2, ERBB3, ERRB4, LRIG1, Survival

\section{Findings}

\section{Background}

Renal cell carcinoma (RCC) consists of various tumor types [1]; clear cell RCC (ccRCC) accounts for approximately 70-80 \% of the RCCs, papillary RCC (pRCC) for $10-15 \%$ of cases, chromophobe RCC (chRCC) for approximately $5 \%$, and collecting duct carcinoma for less than $1 \%$ of RCCs. Approximately 4-5\% of RCCs do not fit the histopathological criteria and are referred to as unclassified carcinomas [1]. The RCC types represent tumor groups with different genetic and molecular properties, as reviewed in [2] and [3]. When RCC types are analyzed collectively, the results predominantly reflect the properties of ccRCC, since this type accounts

\footnotetext{
* Correspondence: marcus.thomasson@onkologi.umu.se

'Department of Radiation Sciences, Umeå University, SE-901 87

Umeå, Sweden

Full list of author information is available at the end of the article
}

for the majority of RCC cases. Previous studies have revealed altered expression of epidermal growth factor (EGF) receptor (EGFR)-family members and their endogenous inhibitor leucine-rich and immunoglobulinlike domains 1 (LRIG1) in renal cell carcinoma (RCC). The EGFR family consists of four receptor tyrosine kinases, EGFR (ERBB1, HER1), ERBB2 (HER2, neu), ERBB3 (HER3), and ERBB4 (HER4) [4], of which downstream intracellular signaling pathways regulate cell proliferation, differentiation, and migration [5]. LRIG1 [6] negatively regulates all four members of the EGFR-family [7-10]. LRIG1 is also a negative regulator of the MET and RET -receptor tyrosine kinases [11,12]. LRIG1 is down-regulated in several cancers and cancer cell lines, including breast cancer and squamous cell carcinoma of the skin and uterine cervix, where low LRIG1 expression correlates with poor patient survival [13-17].

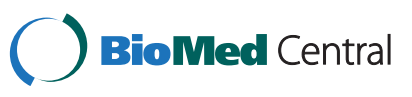




\begin{tabular}{|c|c|c|}
\hline \multicolumn{2}{|l|}{ Total no. of patients } & \multirow{2}{*}{$\begin{array}{l}104 \\
56 / 48\end{array}$} \\
\hline Sex & male/female & \\
\hline Age in years & median (range) & $65(25-85)$ \\
\hline Tumor diameter in $\mathrm{mm}$ & median (range) & $80(30-250)$ \\
\hline Survival in months & Range & $0-130$ \\
\hline Tumor stage (WHO) & । & 26 \\
\hline \multirow[t]{3}{*}{ (As derived from TNM) } & $\|$ & 15 \\
\hline & III & 30 \\
\hline & IV & 33 \\
\hline \multirow[t]{4}{*}{ Tumor grade (Fuhrman) } & 1 & 4 \\
\hline & 2 & 14 \\
\hline & 3 & 60 \\
\hline & 4 & 26 \\
\hline \multirow[t]{4}{*}{ RCC type by histology } & Clear cell & 81 \\
\hline & Papillary & 15 \\
\hline & Chromophobe & 7 \\
\hline & Unclassified & 1 \\
\hline \multicolumn{2}{|c|}{ Patients with known metastasis at diagnosis } & 35 \\
\hline \multicolumn{2}{|c|}{ Patients who died from the disease } & 57 \\
\hline \multicolumn{2}{|c|}{ Patients dead from other causes } & 16 \\
\hline \multicolumn{2}{|c|}{ Patients alive at last follow-up (with disease) } & $31(3)$ \\
\hline
\end{tabular}

Previously, we reported the expression of the EGFRfamily members and LRIG1 in a limited number of RCCpatients $[18,19]$. Here, we extended these studies to a larger patient cohort, and analyzed the RCC types individually.

\section{Methods}

In this study we analyzed tumor samples from 104 patients who underwent nephrectomy at the Department of Urology, Umeå University Hospital, between the years 1986 and 1999 (Table 1). These tumors included 81 ccRCC, 15 pRCC, 7 chRCC, and 1 unclassified carcinoma. Additionally, specimens of histologically verified non-neoplastic kidney cortex were obtained from 27 of the nephrectomized kidneys. RNA was prepared and quantitative real-time reverse transcription- (RT-) PCR of EGFR, ERBB2, ERBB3, ERBB4,
LRIG1, and RN18S1 (18 S rRNA) was performed as previously described $[18,19]$. To correct for differences in RNA quality and quantity, apparent levels of RN18S1 were used to normalize the EGFR, ERBB2-4, and LRIG1 values in each respective RNA sample. To test the reliability of the analysis, all five protein encoding genes were analyzed five times for three different samples. The maximum coefficient of variation and the standard deviation, expressed as a percentage of the mean, was $22 \%$. Patients provided informed consent for the use of both their tumor material and clinical data for studies. This study was approved by the research ethics committee at Umeå University Medical Faculty (No 02-340).

Statistical analysis was performed using nonparametric statistics, as normal distribution of the data could not be assumed. For comparisons between two groups, the Mann-Whitney U-test was used. Comparisons of more than two groups were performed using the Kruskal-Wallis test. Comparisons between coupled samples were performed using the Wilcoxon signedrank test. Correlations were analyzed according to Spearman's rank correlation. Survival analysis was performed by first comparing patients with mRNA expression levels either above or below the median and then subjecting the data to Kaplan-Meier analysis by log-rank test. All P-values were two-sided. All calculations were performed using SPSS 14.0 software.

\section{Results}

The expression of EGFR was higher in all RCC types combined compared to kidney cortex tissue $(\mathrm{P}<0.001)$ (Table 2). This up-regulation was significant for both ccRCC $(\mathrm{P}<0.001)$ and pRCC $(\mathrm{P}=0.016)$, but not for chRCC $(\mathrm{P}=0.257)$ (Figure 1A; Table 2). This is in line with earlier findings by us and others [18,20-24].

$E R B B 2$ expression was significantly reduced in all RCC types combined compared to kidney cortex $(\mathrm{P}=0.003)$; however, reduced expression was only significant in ccRCC $(\mathrm{P}=0.001)$ and not in pRCC or chRCC (Figure 1B). These results indicate that the previously described downregulation of ERBB2 in RCC [19] is actually a result of down-regulation in the ccRCCs.

Table 2 Significant differences in mRNA expression between kidney cortex and the RCC types

\begin{tabular}{lllllll}
\hline & All RCC combined & ccRCC $^{*}$ & pRCC $^{*}$ & chRCC* & Altered expression & Difference RCC typest \\
\hline EGFR & $<0.001$ & 0.001 & 0.016 & NS & Up-regulation & NS \\
ErbB2 & 0.003 & 0.001 & NS & NS & Down-regulation & $<0.001$ \\
ErbB3 & NS & NS & NS & NS & - & NS \\
ErbB4 & 0.001 & $<0.001$ & 0.001 & 0.03 & Down-regulation & NS \\
LRIG1 & NS & 0.015 & NS & NS & Down-regulation & 0.002
\end{tabular}

* P-values were calculated in comparison to kidney cortex using the Mann-Whitney U-test.

† Comparison of the significant differences between the RCC types was performed using the Kruskal-Wallis test.

NS, non-significant. 


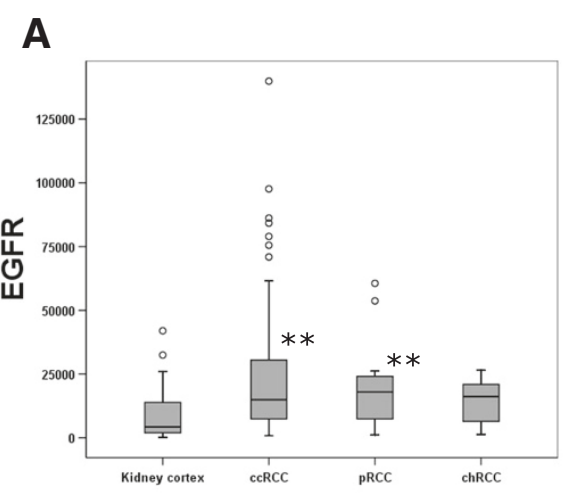

C

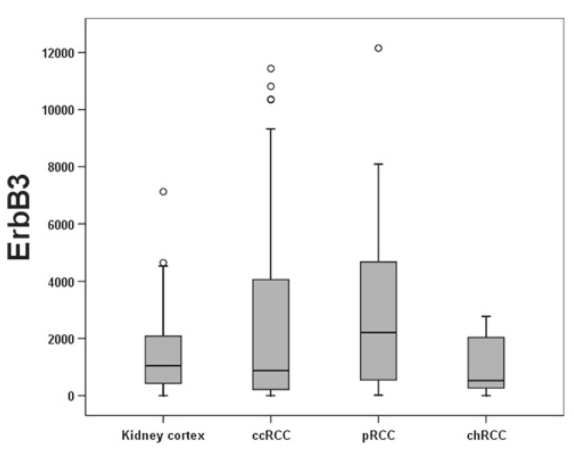

E

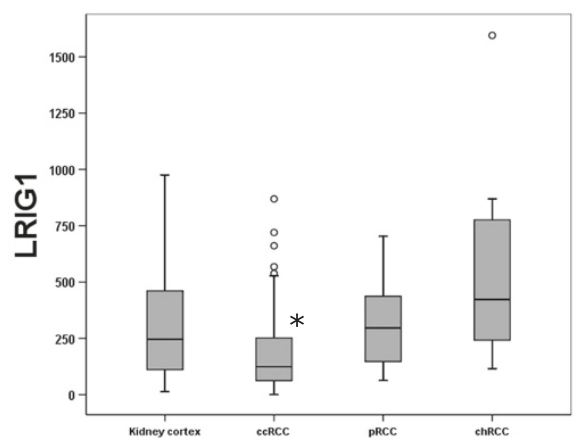

\section{B}

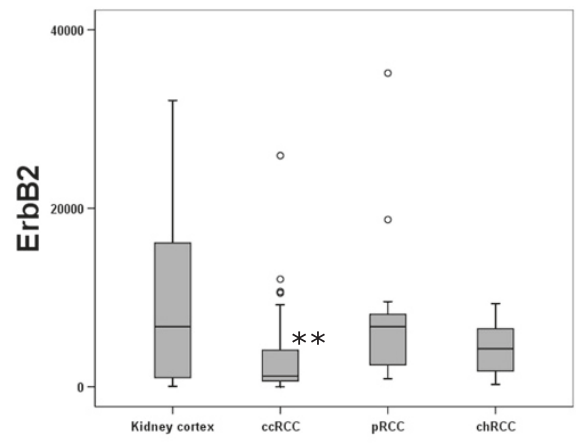

D

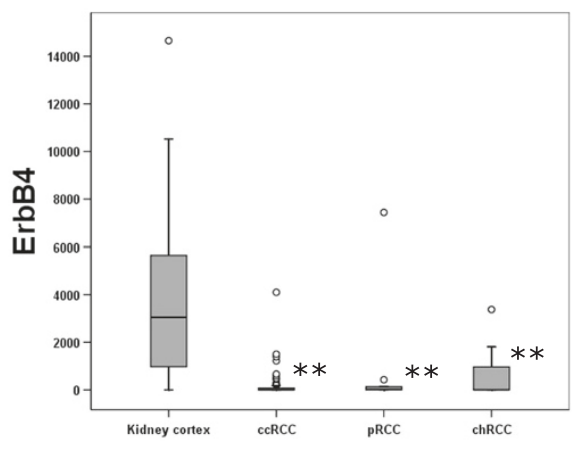

Figure 1 Boxplots of the relative mRNA expression of the EGFR-family members and LRIG1 in both the kidney cortex and the RCC types. Relative mRNA expression of EGFR, ERBB2, ERRB3, ERRB4, and LRIG1 was quantified in kidney cortex $(n=27), \operatorname{ccRCC}(n=81), p R C C(n=15)$, and chRCC $(n=7)$. (A) EGFR mRNA expression was elevated in $C C R C C$ and pRCC compared to kidney cortex. (Increased expression in chRCC was not significant, but expression levels were similar to other RCC groups.) (B) ERBB2 mRNA expression was significantly lower in ccRCC compared to kidney cortex. In pRCC and chRCC, expression did not significantly differ from kidney cortex. (C) ERBB3 mRNA expression was not significantly different between any of the RCC types compared to the kidney cortex. (D) ERBB4 mRNA expression was significantly reduced in all RCC types compared to kidney cortex. (E) LRIGI mRNA expression was significantly lower in ccRCC compared to kidney cortex. In pRCC and chRCC, LRIG1 expression did not significantly differ from kidney cortex. Outlier values are marked ${ }^{\circ}$. Significant differences compared to expression in the kidney cortex are labeled (*) for $\mathrm{P}<0.05$ and $\left(^{* *}\right)$ for $\mathrm{P}<0.01$.

ERBB3 expression was similar in RCC and nonneoplastic kidney cortex, and there was no significant expression difference between RCC types (Figure 1C).

$E R B B 4$ expression was markedly lower in all the different RCC types than in kidney cortex $(\mathrm{P}<0.001)$. There was no difference in ERBB4 expression between the
RCC types (Figure 1D). Thus, the earlier described down-regulation of ERBB4 in RCC [19] was here shown to be prominent in all RCC types analyzed. In fact, no ERBB4 expression could be detected in 51 out of the 104 tumors analyzed. This pronounced down-regulation of ERBB4 may suggest an important 
role for this receptor tyrosine kinase in inhibiting the development of RCC.

The expression of LRIG1 was reduced in ccRCC compared to kidney cortex $(\mathrm{P}=0.020)$. The expression of LRIG1 in pRCC and chRCC was not significantly different from that of kidney cortex (Figure 1E). Thus, the previously described down-regulation of LRIG1 in RCC [18] was restricted to ccRCC. This finding could indicate a tumor suppressive role for LRIG1 in the context of ccRCC that is not present or of reduced importance in other types of RCC.

The expression levels of EGFR, ERBB2-4, and LRIG1 correlated significantly with each other in most cases (Table 3). This was possibly due to LRIG1 expression being up-regulated by receptor activation [7] or due to metholodical issues, e.g. due to variation in the expression of the reference gene, RN18S1. There was a non-significant trend to an inverse correlation $(\mathrm{R}=-0.166 \mathrm{P}=0.058)$ between the expression levels of EGFR and ERBB4. This results is in line with $E G F R$ being up-regulated and ERBB4 being down-regulated in tumors.

The expression levels of ERBB3 within ccRCC were inversely correlated with tumor grade and tumor size $(\mathrm{R}=-0.287, \mathrm{P}=0.009$ and $\mathrm{R}=-0.244, \mathrm{P}=0.027$, respectively). As expression of ERBB3 mRNA was low and did not differ between tumors and kidney cortex or between RCC types, the biological significance of this finding is highly uncertain. No other significant correlation was observed between the expression of EGFR-family members or LRIG1 and the size, grade, or stage of the tumors. Survival analysis comparing patients with tumors expressing above or below median mRNA values of the five genes revealed no significant difference in overall survival or cancer specific survival, neither in ccRCC patients or all RCC patients combined (Additional file 1 Figure S1). The patient groups for the other RCC types

Table 3 Correlation of mRNA expression levels between the analyzed genes

\begin{tabular}{lllllll}
\hline & & EGFR & ErbB2 & ErbB3 & ErbB4 & LRIG1 \\
\hline EGFR & CC & 1.000 & $0.274^{*}$ & $0.425^{*}$ & -0.166 & $0,370^{*}$ \\
& P-value & - & 0.002 & $<0.001$ & 0.058 & $<0.001$ \\
ErbB2 & CC & $0.274^{*}$ & 1.000 & $0.586^{*}$ & $0.375^{*}$ & $0.456^{*}$ \\
& P-value & 0.002 & - & $<0.001$ & $<0.001$ & $<0.001$ \\
ErbB3 & CC & $0.425^{*}$ & $0.586^{*}$ & 1.000 & 0.152 & 0.456 \\
& P-value & $<0.001$ & $<0.001$ & - & 0.082 & 0.000 \\
ErbB4 & CC & -0.166 & $0.375^{*}$ & 0.152 & 1.000 & $0.277^{*}$ \\
& P-value & 0.058 & $<0.001$ & 0.082 & - & 0.001 \\
LRIG1 & $C C$ & $0.370^{*}$ & 0.456 & 0.456 & $0.277^{*}$ & 1.000 \\
& P-value & $<0.001$ & $<0.001$ & $<0.001$ & 0.001 & - \\
\hline
\end{tabular}

CC, Correlation coefficient according to Spearman.

*Significant with P-value $<0.05$. were too small for meaningful survival analyses. The previously described and non-significant association between LRIG1 expression and tumor grade and patient survival [18] was not confirmed in the present and larger study. Therefore, it appears that although LRIG1 may possess a tumor suppressive function in ccRCC, it does not appear to be an important prognostic factor in RCC.

\section{Conclusions}

This study demonstrated that the expression of EGFR, $E R B B 3$ and $E R B B 4$ was similar throughout different RCC types, whereas the expression of ERBB2 and LRIG1 differed between the various types of RCC. This demonstrates potentially important differences and similarities in the expression of the EGFR-family members and LRIG1 genes between different RCC types. Up-regulated gene expression of EGFR compared to kidney cortex was found in all RCC types analyzed. A strong down-regulation of ERBB4 was observed in all RCC types analyzed, while down-regulation of $E R B B 2$ and LRIG1 was found only in ccRCC. The biological and clinical significance of these differences in gene expression warrants further study.

\section{Additional file}

Additional file 1: Figure S1 Kaplan-Meier survival curves of cancer specific survival comparing patients with tumors above and below median expression of all five genes.

\section{Abbreviations}

EGFR: Epidermal growth factor receptor; ERBB: from avian erythroblastosis oncogene B, gene encoding for EGFR; HER: Human EGF receptor; Neu: old designation given to ERRB2 gene when first found in neural mouse tumors; LRIG1: Leucine-rich repeats and immunoglobulin-like domains-1; MET: Gene encoding the hepatocyte growth factor receptor; RCC: Renal cell carcinoma; cCRCC: Clear cell (also called conventional) RCC; chRCC: Chromophobe RCC; pRCC: Papillary RCC; RET: A receptor tyrosine kinase, receptor for members of the glial cell line-derived neurothrophic factor (GDNF) family.

\section{Competing interests}

The authors declare that they have no competing interests.

\section{Acknowledgements}

We would like to thank Gudrun Lindh at the department of Urology for the RNA extractions. This study was supported by grants from The Swedish Cancer Society and The Cancer Research Foundation, Norrland, Sweden.

\section{Author details}

'Department of Radiation Sciences, Umeå University, SE-901 87 Umeå, Sweden. ${ }^{2}$ Department of Surgery and Perioperative Sciences, Urology and Andrology, Umeå University, SE-901 87 Umeå, Sweden.

\section{Author's contribution}

MT performed RT-PCR analysis, statistical analysis, and drafted the manuscript. $\mathrm{HH}$ provided support for the RT-PCR analyses and helped draft the manuscript. BL supervised collection of tumor samples, RNA extracts and clinical data. $\mathrm{RH}$ coordinated the study. All authors participated in the conception and design of the study. All authors have read and approved the final manuscript 


\section{References}

1. Störkel S, Eble J, Adlakha K, Amin M, Blute M, Bostwick D, Darson M, Delahunt B, Iczkowski K: Classification of renal cell carcinoma: Workgroup No. 1. Union Internationale Contre le Cancer (UICC) and the American Joint Committee on Cancer (AJCC). Cancer 1997, 80:987-989.

2. Linehan WM, Vasselli J, Srinivasan R, Walther MM, Merino M, Choyke P, Vocke C, Schmidt L, Isaacs JS, Glenn G, et al: Genetic basis of cancer of the kidney: disease-specific approaches to therapy. Clin Cancer Res 2004, 10:6282S-6289S.

3. Baldewijns MM, van Vlodrop IJ, Schouten LJ, Soetekouw PM, de Bruine AP, van Engeland M: Genetics and epigenetics of renal cell cancer. Biochim Biophys Acta 2008, 1785:133-155.

4. Yarden Y, Sliwkowski M: Untangling the ErbB signalling network. Nat Rev Mol Cell Biol 2001, 2:127-137.

5. Olayioye $M$, Neve $R$, Lane $H$, Hynes $N$ : The ErbB signaling network: receptor heterodimerization in development and cancer. EMBO J 2000, 19:3159-3167.

6. Nilsson J, Vallbo C, Guo D, Golovleva I, Hallberg B, Henriksson R, Hedman H: Cloning, characterization, and expression of human LIG1. Biochem Biophys Res Commun 2001, 284:1155-1161.

7. Gur G, Rubin C, Katz M, Amit I, Citri A, Nilsson J, Amariglio N, Henriksson R, Rechavi G, Hedman H, et al: LRIG1 restricts growth factor signaling by enhancing receptor ubiquitylation and degradation. EMBO J 2004, 23:3270-3281

8. Laederich MB, Funes-Duran M, Yen L, Ingalla E, Wu X, Carraway KL 3rd, Sweeney $C$ : The leucine-rich repeat protein LRIG1 is a negative regulator of ErbB family receptor tyrosine kinases. J Biol Chem 2004, 279:47050-47056.

9. Goldoni S, lozzo RA, Kay P, Campbell S, McQuillan A, Agnew C, Zhu JX, Keene DR, Reed CC, lozzo RV: A soluble ectodomain of LRIG1 inhibits cancer cell growth by attenuating basal and ligand-dependent EGFR activity. Oncogene 2007, 26:368-381.

10. Yi W, Holmlund C, Nilsson J, Inui $S$, Lei T, Itami S, Henriksson R, Hedman H: Paracrine regulation of growth factor signaling by shed leucine-rich repeats and immunoglobulin-like domains 1. Exp Cell Res 2011, 317:504-512.

11. Shattuck DL, Miller JK, Laederich M, Funes M, Petersen H, Carraway KL 3rd, Sweeney C: LRIG1 is a novel negative regulator of the Met receptor and opposes Met and Her2 synergy. Mol Cell Biol 2007, 27:1934-1946.

12. Ledda F, Bieraugel O, Fard SS, Vilar M, Paratcha G: Lrig1 is an endogenous inhibitor of Ret receptor tyrosine kinase activation, downstream signaling, and biological responses to GDNF. J Neurosci 2008, 28:39-49.

13. Miller JK, Shattuck DL, Ingalla EQ, Yen L, Borowsky AD, Young LJ, Cardiff RD, Carraway KL 3rd, Sweeney C: Suppression of the negative regulator LRIG1 contributes to ErbB2 overexpression in breast cancer. Cancer Res 2008, 68:8286-8294

14. Hedman H, Nilsson J, Guo D, Henriksson R: Is LRIG1 a tumour suppressor gene at chromosome 3p14.3? Acta Oncol 2002, 41:352-354.

15. Tanemura A, Nagasawa T, Inui S, Itami S: LRIG-1 provides a novel prognostic predictor in squamous cell carcinoma of the skin: immunohistochemical analysis for 38 cases. Dermatol Surg 2005, 31:423-430.

16. Lindstrom AK, Ekman K, Stendahl U, Tot T, Henriksson R, Hedman $H_{\text {, }}$ Hellberg D: LRIG1 and squamous epithelial uterine cervical cancer: correlation to prognosis, other tumor markers, sex steroid hormones, and smoking. Int J Gynecol Cancer 2008, 18:312-317.

17. Krig SR, Frietze S, Simion C, Miller JK, Fry WH, Rafidi H, Kotelawala L, Qi L, Griffith OL, Gray JW, et al: Lrig1 Is an Estrogen-Regulated Growth Suppressor and Correlates with Longer Relapse-Free Survival in ER \{alpha\}-Positive Breast Cancer. Mol Cancer Res 2011, 9:1406-1417.

18. Thomasson M, Hedman H, Guo D, Ljungberg B, Henriksson R: LRIG1 and epidermal growth factor receptor in renal cell carcinoma: $A$ quantitative RT-PCR and immunohistochemical analysis. $\mathrm{Br} J$ Cancer 2003, 89:1285-1289.

19. Thomasson M, Hedman $H$, Junttila TT, Elenius K, Ljungberg B, Henriksson R: ErbB4 is downregulated in renal cell carcinoma-a quantitative RT-PCR and immunohistochemical analysis of the epidermal growth factor receptor family. Acta Oncol 2004, 43:453-459.

20. Hofmockel G, Riess S, Bassukas I, Dammrich J: Epidermal growth factor family and renal cell carcinoma: expression and prognostic impact. Eur Urol 1997, 31:478-484.

21. Yoshida K, Tosaka A: Epidermal growth factor binding by membranes of human renal cell carcinomas: establishment of an epidermal growth factor receptor assay for clinical use. Int J Urol 1994, 1:319-323.
22. Lager D, Slagel D, Palechek P: The expression of epidermal growth factor receptor and transforming growth factor alpha in renal cell carcinoma. Mod Pathol 1994, 7:544-548.

23. Ljungberg B, Gafvels M, Damber J: Epidermal growth factor receptor gene expression and binding capacity in renal cell carcinoma, in relation to tumor stage, grade and DNA ploidy. Urol Res 1994, 22:305-308.

24. Sakaeda T, Okamura N, Gotoh A, Shirakawa T, Terao S, Morioka M, Tokui K, Tanaka H, Nakamura T, Yagi M, et al: EGFR mRNA is upregulated, but somatic mutations of the gene are hardly found in renal cell carcinoma in Japanese patients. Pharm Res 2005, 22:1757-1761.

doi:10.1186/1756-0500-5-216

Cite this article as: Thomasson et al: Gene expression pattern of the epidermal growth factor receptor family and LRIG1 in renal cell carcinoma. BMC Research Notes 2012 5:216.

\section{Submit your next manuscript to BioMed Central and take full advantage of:}

- Convenient online submission

- Thorough peer review

- No space constraints or color figure charges

- Immediate publication on acceptance

- Inclusion in PubMed, CAS, Scopus and Google Scholar

- Research which is freely available for redistribution 